\title{
Das Heilige Wundkraut
}

\section{Iris Ritzmann}

Prof. Dr. med. et lic. phil., Mitglied der Redaktion Medizingeschichte

Eine wahre Gabe Gottes sei es, das Heilige Wundkraut. Nicht nur, dass es Wunden viel besser als andere Arzneipflanzen heile. Es vertreibe auch zuverlässig jede Lungenkrankheit, sogar die gefürchtete Schwindsucht. So lernt man aus den Kräuterbüchern des 16. und 17. Jahrhunderts. In komplizierten Beschreibungen erklärten die Autoren ihrer europäischen Leserschaft, wie man das amerikanische Kraut anwenden konnte. Viel einfacher und sinnvoller war es da, ein erklärendes Bild mit abzudrucken. Dies tat Adam Lonitzer, Stadtarzt in Frankfurt, in den späteren Auflagen seines «Kräuterbuchs». Dieses Sammelsurium von Wissenswertem und Kuriosem aus unterschiedlichen Naturbüchern erschien zwischen 1557 und 1783 in 27 Auflagen, was wohl vor allem der geschickten Verheiratung Lonitzers mit der Tochter des Verlegers Christian Egenolff zu verdanken war.
Zu sehen ist ein Indianer mit einem Trichter, der aus einem Palmblatt gedreht wurde. Die getrockneten Blätter der Heilpflanze, die sich im Trichter befinden, sind bereits angezündet und entwickeln eine heftige Dampfwolke. Hält man sich den Trichter an den Mund und saugt, gelangt der Dampf in die Lungen, wo er seine Heilkraft entfalten kann.

Worum handelte es sich beim Heiligen Wundkraut? Die Pflanze sei in Frankreich nach dem portugiesischen Gesandten Nicotio benannt worden, und die Spanier hätten dem Wunderkraut den Namen Tabaco gegeben, berichtet Lonitzer. Richtig, das einstige Heilmittel gegen Lungenleiden ist nichts anderes als die Tabakpflanze, die heute als schädliches Lungengift gilt.

\section{Bildnachweis}

Museum für medizinhistorische Bücher Muri (mmbm.ch)

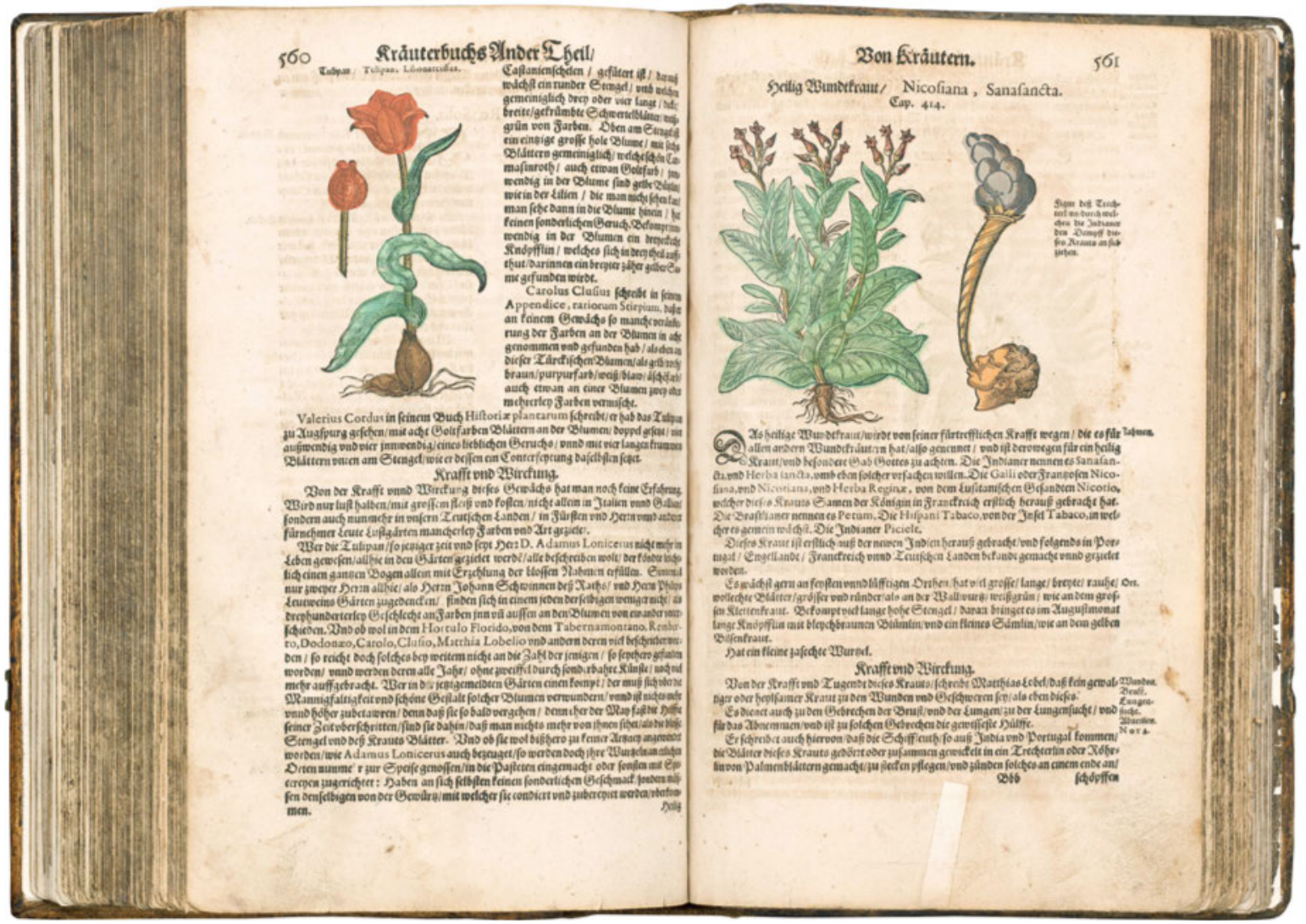

Heiliges Wundkraut oder Nicosiana, in Adam Lonitzer: Vollständiges Kräuter-Buch. Altkoloriertes Exemplar, herausgegeben von Peter Uffenbach, Mainz 1630, Sammlung Dr. Franz Käppeli. 